Cad. Benjaminianos, Belo Horizonte, v. 13, n. 2, p. 207-227, 2017

\title{
Baudelaire, Benjamin, a modernidade: uma ética?
}

\section{Baudelaire, Benjamin, the modernity: an ethic?}

\author{
Marcelo Santana Ferreira \\ Universidade Federal Fluminense (UFF), Rio de Janeiro, Rio de Janeiro / Brasil \\ mars.ferreira@hotmail.com
}

\section{Gabriel Lacerda de Resende}

Universidade Federal Fluminense (UFF), Rio de Janeiro, Rio de Janeiro / Brasil gablacres@gmail.com

Resumo: O presente artigo aborda uma das possíveis relações entre o pensamento de Walter Benjamin e parte da obra de Charles Baudelaire. Considera-se que a defesa da crítica no pensamento de Benjamin assenta-se na relação dialética entre distância e proximidade, que também se exprime na formulação de sua concepção de história materialista. Ao se indicar diferentes momentos da obra de Benjamin, defende-se que o pensador evoca o que havia reconhecido em Baudelaire: a definição de modernidade como uma atitude. Por intermédio desta interpretação, busca-se defender que, a partir de sua leitura de Baudelaire, Benjamin considera que a tarefa do crítico e do historiador materialista seja a de, inicialmente, fundar uma distância em relação a sua própria época, ao mesmo tempo em que se reconhece aquilo que lhe identifica. Distância e proximidade subsidiam, portanto, a articulação de uma ética, apreensível em distintos momentos da obra de Benjamin.

Palavras-chave: modernidade; ética; distância; proximidade.

Abstract: This article discusses one of the possible relations between the thought of Walter Benjamin and part of the work of Charles Baudelaire. It is considered that the defense of the critique in the thought of Benjamin is based on the dialectic relation between distance and proximity, that also is expressed in the formulation of his 
conception of materialistic history. In pointing out different moments of Benjamin's work, it is argued that the thinker evokes what he had recognized in Baudelaire : the definition of modernity as an attitude. Through this interpretation, it seeks to defend that, from his reading of Baudelaire, Benjamin considers that the task of the critic and the materialist historian is to, initially, establish a distance in relation to his own time, at the same time in that it is recognized what identifies one period of history. Distance and proximity therefore subsidize the articulation of an ethic, apprehensible at different moments in Benjamin's work.

Keywords: modernity; ethic; distance; proximity.

\section{Introdução}

A modernidade tem múltiplos sentidos no pensamento de Walter Benjamin. Uma de suas mais importantes inspirações é reconhecida na obra de Charles Baudelaire, principalmente em sua poética. No entanto, em um texto em prosa de Baudelaire, encontramos imagens do sentido de uma época que, provavelmente, fertilizaram o modo como Benjamin se posiciona em relação à modernidade. Em $O$ pintor da vida moderna, Baudelaire (2006) defende uma compreensão da modernidade como a articulação de uma atitude, em que não se trata de, simplesmente, compreender o que uma época significa, mas de instalar-se, ética e esteticamente, na transitoriedade do que é moderno. Existiriam tantas modernidades quanto a acuidade estética permitiria vislumbrar. Estas modernidades, no caso de Baudelaire, empuxam o artista para um abrigo no que é transitório e não é modelar. Sob os signos da transitoriedade e da articulação de uma ontologia precária do ser da poesia, Baudelaire parece propiciar a Benjamin importantes imagens que serão cruciais para que o pensador alemão compreenda que a crítica só pode realizar-se na duplicidade de uma fidelidade e um pessimismo em relação à época em que se está instalado.

\section{2 Época: fidelidade e pessimismo}

Walter Benjamin se referiu a muitos poetas e escritores a fim de defender uma tarefa renovada para a filosofia, tocado, definitivamente, pela necessidade de configuração de uma concepção de experiência que não sucumbisse a teleologia do progresso técnico - traduzido, tradicionalmente, como progresso do gênero humano - e nem ao apelo da 
empatia entre os tempos históricos, como se não houvesse uma distância entre passado e presente que requisitasse que, cuidadosamente, nos déssemos conta de onde nos encontramos. Insatisfeito com a perspectiva de que o tempo histórico transcorra por avanços, recuos e decadências, o pensador procura estabelecer uma aproximação a exercícios estéticos como o de Baudelaire, em que a modernidade é compreendida como uma espécie de revide ao singular e ao transitório de uma época. Charles Baudelaire apresenta uma imagem importante de um exercício estético que encontra um direcionamento na crítica benjaminiana:

A modernidade é o transitório, o efêmero, o contingente, é a metade da arte, sendo a outra metade o eterno e o imutável. Houve uma modernidade para cada pintor antigo: a maior parte dos belos retratos que nos provêm das épocas passadas está revestida de costumes da própria época. São perfeitamente harmoniosos; assim, a indumentária, o penteado e mesmo o gesto, o olhar e o sorriso (cada época tem seu porte, seu olhar e seu sorriso) formam um todo de completa vitalidade. Não temos o direito de desprezar ou de prescindir desse elemento transitório, fugidio, cujas metamorfoses são tão frequentes. Suprimindo-os, caímos forçosamente no vazio de uma beleza abstrata e indefinível, como a da única mulher antes do primeiro pecado (BAUDELAIRE, 2006, p. 860).

Encontramos em Walter Benjamin uma preocupação - em termos de composição de uma historiografia materialista e de uma crítica estética que empreenda o reconhecimento da relação entre o teor coisal e o teor de verdade de uma obra - de não nos esquivarmos da época em que nos coube viver. Nenhum saudosismo ou idealização do passado, mas uma tarefa de articular uma concepção de tempo que não sucumba a imposição do temposucessão. A "metade da arte" proposta por Baudelaire em sua compreensão da modernidade se alia ao eterno e imutável. Atentar-se ao transitório parece ser uma atitude que prescreve, em Benjamin, uma relação renovada com o presente, como se pode depreender de suas análises da pobreza de experiência ${ }^{1}$ privada e de toda a humanidade nas sociedades modernas:

\footnotetext{
${ }^{1}$ Sabemos da importância que o conceito de experiência assume na obra de Walter Benjamin. No presente artigo, um lampejo do conceito se desenha. A complexidade do conceito e a fundamental discussão de Benjamin a partir da espessura etimológica da palavra em alemão merecem discussões mais amplas, algumas delas já realizadas. Indicamos o fundamental estudo de Agamben (2005) sobre o conceito.
} 
Pobreza de experiência: não se deve imaginar que os homens aspirem a novas experiências. Não, eles aspiram a libertar-se de toda experiência, aspiram a um mundo em que possam ostentar tão pura e tão claramente sua pobreza externa e interna, que algo de decente possa resultar disso. Nem sempre eles são ignorantes ou inexperientes. Muitas vezes, podemos afirmar o oposto: eles "devoraram" tudo, a "cultura" e os "homens", e ficaram saciados e exaustos. "Vocês estão todos tão cansados - e tudo porque não concentraram todos os seus pensamentos num plano totalmente simples, mas absolutamente grandioso" (BENJAMIN, 2008, p. 118).

Benjamin, no excerto anterior, retoma - já que, em escritos juvenis, já havia apresentado a importância do conceito - a consideração sobre experiência, a partir da defesa de uma estirpe de artistas e pensadores que exprimem um pessimismo e uma fidelidade simultâneos com o seu próprio tempo: começar com pouco, construir com pouco, acatar que o patrimônio cultural não se vincula mais, no século $\mathrm{XX}$, aos indivíduos a partir de uma experiência. No mesmo ensaio, Benjamin (2008, p. 106) ousa considerar algumas expressões culturais do início do século XX como indicativas da destinação de nossa pobreza de experiência, como no caso da incitação ao sonho após a fadiga resultante da relação com uma metrópole em que somos permanentemente excitados pela quantidade avassaladora de estímulos externos. A crítica à pobreza de experiência se coaduna com o diagnóstico do esvaziamento da transmissibilidade, paradigma da situação que identifica a modernidade: a impossibilidade de se evocar a experiência para lidar com os mais jovens, o silêncio dos combatentes que retornam dos campos de batalha da I Guerra Mundial. No entanto, partir do pouco que se tem significa não se evadir de sua própria época. Aqui, nos parece que a modernidade se aparenta com uma atitude em Walter Benjamin (2008), que sugere uma barbárie positiva, herdeira do "caráter destrutivo" e que identifica a estirpe de homens a que o pensador se refere no ensaio: de Descartes a Brecht, transitando pela apropriação singular da personagem Mickey Mouse:

(...) o que resulta para o bárbaro dessa pobreza de experiência? Ela o impele a partir para a frente, a começar de novo, a contentar-se com pouco, a construir com pouco, sem olhar nem para a direita nem para

\footnotetext{
${ }^{2}$ Como se pode depreender de ensaios como Experiência e pobreza de 1933 e Teses sobre o conceito de história de 1940.
} 
a esquerda. Entre os grandes criadores sempre existiram homens implacáveis que operaram a partir de uma tabula rasa. Queriam uma prancheta: foram construtores (BENJAMIN, 2008, p. 106).

No excerto anterior, se evoca a perspectiva construtiva que o pensador judeu alemão sugere ao defender uma concepção materialista de história por oposição a uma perspectiva continuísta, assentada em um tempo homogêneo e vazio. ${ }^{3}$ Darmo-nos conta de onde nos encontramos: aqui Baudelaire e Benjamin parecem estar muito próximos. A modernidade em Baudelaire, a partir dos elementos reconhecíveis no fragmento de $O$ pintor da vida moderna, se assenta no apreço ao duplo registro do efêmero e do eterno, o que, certamente, se pode reconhecer, também, na relação entre o intensivo e o extensivo em Walter Benjamin.

\section{Uma distância crítica}

Se uma consideração constelar dos escritos de Walter Benjamin permite que se apreenda sua concepção de modernidade como uma atitude, talvez esta possa ser definida como a instauração, no mesmo movimento, de uma distância em relação ao passado - ao que já não somos - e de um trabalho sobre as linhas que constituem as possibilidades abertas pela atualidade. $\mathrm{O}$ primeiro elemento dessa proposição pode ser elucidado a partir de algumas colocações benjaminianas presentes no ensaio sobre o surrealismo e em um fragmento de Rua de mão única; o segundo pode ser encontrado com mais ossatura nos escritos sobre Baudelaire.

Em Espaços livres para alugar, Benjamin constata que a crítica teria perdido seu lugar para a propaganda; enquanto a primeira seria "uma questão de distância certa" (BENJAMIN, 2013, p. 50), a segunda obedeceria à proximidade e ao ritmo impostos pela dinâmica do capitalismo, em que "as coisas tornaram-se excessivamente agressivas para a sociedade humana" (BENJAMIN, 2013, p. 50). Assim, mais

\footnotetext{
${ }^{3}$ Nas célebres Teses sobre o conceito de história, de 1940, Walter Benjamin (2008) propõe muitas imagens do que se seria a temporalidade vazia e homogênea em curso nas historiografias dominantes da transição do século XIX ao século XX, que ainda vigoram na dificuldade política e epistêmica de compreensão da emergência e consolidação do nazismo na Alemanha. Opondo-se ao tempo vazio e homogêneo dessas historiografias, o pensador sugere que à história concerne um tempo saturado de "agoras", que impõem, por intermédio da acuidade de coletividades e do historiador materialista, um freio à norma teleológica.
} 
do que fazer coro à "estultícia daqueles que lamentam o declínio da crítica" (BENJAMIN, 2013, p. 50) - o que já indica, aliás, o repúdio à uma relação nostálgica com um passado para sempre perdido -, seria preciso formular um conceito de crítica capaz de operar a partir das condições objetivas de determinada experiência histórica. Depreende-se do texto benjaminiano que a publicidade teria logrado fazê-lo, fundando sua relação com o espectador/consumidor justamente na proximidade inexorável e na fugacidade da experiência da cidade moderna.

Gatti (2009) defende que uma aproximação entre Rua de mão única e o ensaio sobre o surrealismo fornece uma chave importante para tecermos o alcance das reflexões benjaminianas a respeito da redefinição da crítica - e, por conseguinte, do papel do crítico frente às urgências de sua época. Se até então Benjamin estivera ocupado em tornar-se o maior crítico literário da Alemanha, a aproximação com o surrealismo fornece novas inteligibilidades entre as dimensões estética e política, de modo que tentará articular alguns procedimentos artísticos dos surrealistas a uma leitura atenta da experiência política das cidades das primeiras décadas do século XX. O resultado dessa urdidura é a instauração de um procedimento crítico que já não pode ser realizado distante de seu objeto; todo o contrário, o crítico deve estar à altura do acontecimento que lhe ocupa - e, nesse caso, trata-se de estar ao rés do chão da cidade, com os olhos na "poça de fogo" que reflete o anúncio do letreiro neon. Vejamos como Benjamin evoca, de modo aparentemente contraditório, a questão do topos da crítica nos textos mencionados.

Em Espaços livres para alugar, ele escreve:

A estultícia daqueles que lamentam o declínio da crítica. Porque a hora da crítica já há muito tempo que passou. A crítica é uma questão de distância certa. O seu elemento é o de um mundo em que o que importa são as perspectivas e os pontos de vista, e em que ainda era possível assumir uma posição. Entretanto, as coisas tornaram-se excessivamente agressivas para a sociedade humana. A 'imparcialidade', o 'olhar livre' são mentiras, se não mesmo a mais ingênua expressão da pura incompetência. O olhar hoje mais essencial, o olho mercantil que penetra no coração das coisas, chama-se propaganda. Esta arrasa o espaço livre da contemplação e aproxima tanto as coisas, coloca-as tão debaixo do nariz quanto o automóvel que sai da tela de cinema e cresce, gigantesco, tremeluzindo em direção a nós. E do mesmo modo que o cinema 
não oferece móveis e fachadas a uma observação crítica completa, mas dá apenas a sua espetacular, rígida e repentina proximidade, também a propaganda autêntica transporta as coisas para primeiro plano e tem um ritmo que corresponde ao de um bom filme. Com isso, foi-se de vez a 'objetividade', e diante das imagens hiperdimensionais nas paredes das casas, onde o 'Chlorodont' e o 'Sleipnir' estão ao alcance das mãos de gigantes, o sentimentalismo curado liberta-se à americana, como aquelas pessoas a quem já nada move nem comove, e que aprendem novamente a chorar no cinema. Mas para o homem da rua, aquilo que dele aproxima assim as coisas, o que estabelece o contato decisivo com elas, é o dinheiro. E o crítico pago, que manipula o valor dos quadros na galeria de arte do marchand, sabe sobre eles coisas que, se não são melhores, são certamente mais importantes do que as que sabe o amador de arte que os vê na vitrine. Solta-se do tema da obra um calor que dá asas ao seu sentimento. O que é que torna, afinal, a propaganda tão superior à crítica? Não será aquilo que diz a escrita elétrica e móvel do anúncio - mas a poça de fogo que a reflete no asfalto" (BENJAMIN, 2013, p.50-51, grifo original).

Já nas primeiras linhas de $O$ surrealismo - o último instantâneo $d a$ inteligência européia, Benjamin retoma o tema da posição e da distância necessárias ao exercício da crítica, embora sob um viés aparentemente contraditório em relação ao texto de Rua de mão única:

O crítico pode instalar nas correntes espirituais uma espécie de usina geradora quando elas atingem um declive suficientemente íngreme. No caso do surrealismo, esse declive corresponde à diferença de nível entre a França e a Alemanha. O movimento que brotou na França, em 1919, [...] pode ter sido um estreito riacho, alimentado pelo úmido tédio da Europa de após-guerra e pelos últimos regatos da decência francesa. [...] Mas os eruditos que ainda hoje são incapazes de determinar 'as origens autênticas' do movimento [...] parecem-se um pouco com uma junta de técnicos que, depois de muito observarem uma fonte, chegam à convicção de que o córrego não poderá jamais impulsionar turbinas. $\mathrm{O}$ observador alemão não está situado na fonte. É sua oportunidade. Ele está situado no vale. É capaz de avaliar as energias do movimento (BENJAMIN, 2008, p.21). 
Gatti (2009) já havia detectado a aparente contradição no tratamento da distância crítica nos dois textos: se em Rua de mão única o distanciamento necessário ao crítico não era mais possível, dadas as condições materiais da cidade moderna, no texto sobre o surrealismo a distância é justamente a vantagem do crítico alemão sobre o francês: posicionado longe da fonte, ele é "capaz de avaliar as energias do movimento" (BENJAMIN, 2008, p.21). O comentador acrescenta, no entanto, que o lamento de Benjamin

não censura o distanciamento como elemento da crítica, mas sua deturpação pela crítica contemporânea que, ao traduzi-lo erroneamente por imparcialidade, não reconhece os novos desafios colocados à crítica nem a necessidade de sua transformação (GATTI, 2009, p. 77).

Assim, a questão de Benjamin é menos o abandono completo e total da distância como elemento fundamental da crítica do que um apelo à transformação dessa atividade, de modo que ela possa estar à altura da atualidade. É precisamente partindo de uma radical atenção à materialidade de sua época que o crítico poderá instaurar uma cesura no próprio presente, engendrando a um só tempo as condições de sua criticabilidade e as possibilidades de sua transformação.

Que meios possui o crítico para realizar essa operação de cesura no presente, e que papel, afinal, teria a propaganda nesse processo? Gatti sugere que o trunfo dos reclames é que a sua apreensão se dá a partir de imagens tecidas na concretude da cidade. Não à toa, Benjamin evoca, no fragmento supracitado, as "imagens hiperdimensionais nas paredes das casas, onde o 'Chlorodont' e o 'Sleipnir' estão ao alcance das mãos de gigantes" (BENJAMIN, 1985, p. 21). Deste modo, à perda de objetividade ocasionada pela proximidade e velocidade fugaz da experiência urbana, a crítica deveria reagir pelo mesmo procedimento da publicidade, elaborando imagens da cidade: "A reconstrução da crítica é também uma reformulação da percepção urbana pela noção de imagem" (GATTI, 2009, p. 79). Não é outra a indicação de Benjamin na última frase, enigmática, de Espaços livres para alugar: não se trata de adotar ingenuamente os procedimentos da propaganda, mas compreender que a sua proximidade e diretividade permitem uma insólita justaposição com os variados elementos da cidade, revelando imagens que são índices de uma legibilidade renovada da experiência urbana. $\mathrm{O}$ crítico deve trabalhar sobre as diversas linhas que 
compõem a atualidade, desatando os nós que aparecem como inexoráveis e produzindo conexões em direção a uma diferenciação da época em relação a ela mesma. Eis o novo topos da crítica.

\section{$* * *$}

Em um ensaio sobre As afinidades eletivas, de Goethe, Walter Benjamin apresenta uma emblemática imagem do que seria a crítica:

Se, por força de um símile, quiser-se contemplar a obra em expansão como uma fogueira em chamas vívidas, pode-se dizer então que o comentador se encontra diante dela como o químico, e o crítico semelhantemente ao alquimista. Onde para aquele apenas madeira e cinzas restam como objetos de sua análise, para este tão somente a própria chama preserva um enigma: o enigma daquilo que está vivo. Assim o crítico levanta indagações quanto à verdade cuja chama viva continua a arder sobre as pesadas achas do que foi e sobre a leve cinza do vivenciado (BENJAMIN, 2009, p. 13-14).

Claudia Castro (2001) defende que, malgrado a preocupação especificamente literária de Benjamin à época da redação desse texto, nele vislumbramos o gérmen de sua teoria do conhecimento e, por extensão, de sua concepção de crítica, intimamente ligada a um tratamento singular da história. Seguindo o texto benjaminiano, à distinção entre o químico e o alquimista somar-se-ia uma separação entre o teor coisal (Sachgehalt) e o teor de verdade (Wahrheitsgehalt) de uma obra: o primeiro corresponde à camada empírica da obra, sua materialidade aparente, limitada e determinada pelas condições históricas objetivas da época em que ela aparece - a madeira e as cinzas, nos termos da imagem de Benjamin; já o teor de verdade relaciona-se com essa dimensão enigmática, nãoaparente, que não desponta de forma imediata na configuração sensível da obra - a chama viva, objeto de indagação do crítico. Com essa definição, Walter Benjamin produz um importante deslocamento na tarefa crítica e na concepção de obra de arte:

Contra uma interpretação classicista da obra de arte, para a qual a verdade se manifesta integralmente na aparência - o que é o arquétipo da beleza -, Benjamin assinala uma fratura na obra: aparência e verdade, embora intimamente relacionadas, não coincidem (CASTRO, 2001, p. 18). 
Tal distinção garantiria a apreensão do paradoxo específico das obras de arte: gestadas numa época específica, a partir de condições históricas muito objetivas, relacionam-se com uma dimensão que ultrapassa todos esses determinantes. Assim, é só quando o teor coisal da obra é exposto ao processo histórico - às interferências do tempo - que emerge seu teor de verdade. Submetido à história, o teor coisal de uma obra transmuta-se em ruínas que revelam seu teor de verdade. Quanto maior a distância entre o passado em que a obra foi concebida e o presente o qual ela é convocada a indagar, maior a sua criticabilidade. É só sob o efeito da história que a obra pode desvelar as múltiplas densidades de seu sentido:

[...] a eternidade própria às obras de arte coincide com a experiência da sua historicidade autêntica. Ela não provém de um pretenso valor eterno das mesmas, mas daquilo que advém do seu próprio processo de formação, do seu caráter eminentemente histórico, que só o tempo revela (CASTRO, 2001, p. 24).

É, portanto, sob o signo da morte, da destruição, da ação do tempo, que a crítica pode desvelar a ligação de uma obra com a verdade. $\mathrm{Na}$ tentativa de não coincidir o seu próprio procedimento com o de uma relação com o conhecimento apenas movida pelo acúmulo de saber sobre as coisas na linearidade de um tempo sempre igual a si mesmo, será a interrupção provocada pela obra lançada ao tempo que intercederá por uma renovada relação com a verdade. $\mathrm{O}$ êthos benjaminiano se encaminha a uma consideração da obra de arte em sua duração temporal e em seu inacabamento citável na remissão à infinitude das expressões da beleza. A crítica não se instala sem o reconhecimento das marcas temporais que constituem o próprio sentido da obra de arte. Como compreende Katia Muricy, a relação entre intensividade e extensividade em Benjamin traz marcas significativas de sua interpretação da poética de Baudelaire:

No âmbito das ideias - eliminada a noção de sujeito-objeto e, consequentemente, a questão do método como garantia de certeza - a interpretação, atenta à temporalidade intensiva de ideias e obras de arte, propõe-se a estabelecer elos intensivos capazes de arrancar a obra da repetição a que lhe condenara a continuidade linear, no caso da poesia de Baudelaire, da história da literatura, para lhe dar uma nova origem no presente da leitura. (MURICY, 1998, p. 195). 
A interpretação arranca a obra de arte da continuidade artificial imposta à mesma. $\mathrm{O}$ gesto interpretativo de Benjamin em relação à poética de Baudelaire recoloca a reflexão sobre distância e proximidade, reconhecível, também, na compreensão do legado de Nikolai Leskov em relação à constatação de que não há mais espaço para a sabedoria na modernidade. Quando se tratava de compreender Leskov como um dos últimos narradores, Benjamin também evocou a distância em que a modernidade poderia ser pensada/articulada em relação a época dos narradores da tradição oral:

Descrever um Leskov como narrador não significa trazê-lo mais perto de nós, e sim, pelo contrário, aumentar a distância que nos separa dele. Vistos de uma certa distância, os traços grandes e simples que caracterizam o narrador se destacam nele. Ou melhor, esses traços aparecem, como um rosto humano ou um corpo de animal aparecem num rochedo, para um observador localizado numa distância apropriada e num ângulo favorável. Uma experiência quase cotidiana nos impõe a exigência dessa distância e desse ângulo de observação (BENJAMIN, 2008, p. 197).

O ensaio sobre a obra de Nikolai Leskov, originalmente publicado em 1936, traz a preocupação com o estabelecimento de uma compreensão daquilo que se impõe ao observador. Além disto, a relação com o passado e com a obra de Leskov não tende a ser abreviada com possíveis identificações entre o presente e o passado. O ângulo de observação se estrutura como possibilidade de estabelecimento de uma crítica. Há algo na obra de Leskov que pode ser reconhecido agora, a partir dos problemas específicos que a própria época coloca, politicamente e epistemologicamente. Talvez sob o signo da interrupção, a possibilidade de se relacionar com o passado indique a direção para uma nova conceptualização da memória e do tempo, uma vez que a continuidade é suspensa por intermédio da magnitude da recordação, como se percebe na literatura proustiana e se defende na problematização da ciência histórica em Benjamin. Como proposto por Muricy (1998, p.194), tal como há em Marcel Proust uma leitura da atitude de Baudelaire como um seccionamento do tempo por intermédio da rememoração, Benjamin destacara o desejo de interrupção do curso do mundo. De acordo com Benjamin,

Interromper o curso do mundo - esse era o desejo mais profundo em Baudelaire. O desejo de Josué. Não tanto o profético, pois ele 
não pensava em retorno. Desse desejo nasciam sua violência, sua impaciência e sua ira; dele também nasciam as tentativas sempre renovadas de atingir o mundo no coração ou de fazê-lo dormir, cantando. É por causa desse desejo que, em suas obras, ele faz com que a morte esteja acompanhada de suas exortações.(BENJAMIN, 1994, p.160).

A cidade grande e a multidão se tornam temas privilegiados da poética de Baudelaire e o desejo de interrupção do curso do mundo se exprime de variadas formas, como no texto em prosa já citado em que se considera a modernidade. A interrupção do curso do mundo se envolve com a interrogação da eventual condição de antiguidade para o que se configura como moderno e com a incontornável relação entre o fugidio e o imutável. Para a presente argumentação, abrigar-se naquilo que configura a especificidade de uma época se encaminha à consideração de uma ontologia da poética. Nas multidões, objeto de grande interesse das ciências humanas do século XIX, o poeta em Baudelaire encontra um abrigo. Charles Baudelaire encontra nas multidões o exato contraponto da interioridade inflada da vivência burguesa. Um poeta que estabelece uma estranha esgrima com as coisas e que ainda pode se ancorar em uma sensibilidade rasurada pelo alarido da cidade - Paris do século XIX - fornece a Walter Benjamin importantes subsídios para a consideração de uma perspectiva crítica e de uma abordagem historiográfica que não idealiza o tempo. Sobre as multidões, encontramos em Baudelaire o seguinte:

Aquele que desposa facilmente a multidão conhece gozos febris, de que estarão privados para sempre o egoísta, fechado como um cofre, e o preguiçoso, encaramujado feito um molusco. Ele adota como suas todas as profissões, todas as alegrias e todas as misérias que as circunstâncias lhe deparam.

Aquilo a que os homens chamam amor é muito pequeno, muito limitado e muito frágil, comparado a essa inefável orgia, a essa sagrada prostituição da alma que se dá inteira, poesia e caridade, ao imprevisto que surge, ao desconhecido que passa (BAUDELAIRE, 2006, p. 289).

A acuidade estética de Baudelaire encontra em Benjamin uma ampliação com vistas à elaboração de uma perspectiva política sobre o tempo histórico. Com o desejo de superar o individualismo e a tradição psicologizante da relação entre os indivíduos e o tempo - que se exprimem 
no campo da historiografia como tendências empáticas e fatalistas do curso do tempo - Benjamin sugere que a interrupção da cronologia necessita de uma tradução epistêmica no reconhecimento de fios de temporalidade perdidos, esquecidos compulsoriamente pelas visões hegemônicas. Estar atento ao que passa, abandonando a concepção do passado como algo encerrado, bem como a concepção da tradição como um puro em si mesmo. Vejamos se nas Teses sobre o conceito de história, especificamente nas teses V e VI, Benjamin sugere algo próximo a uma interrupção da qual se pode inaugurar outras perspectivas sobre o tempo histórico: "A verdadeira imagem do passado perpassa, veloz. O passado só se deixa fixar, como imagem que relampeja irreversivelmente, no momento em que é reconhecido." (BENJAMIN, 2008, p. 224) e, também,

Articular historicamente o passado não significa conhecê-lo 'como ele de fato foi'. Significa apropriar-se de uma reminiscência, tal como ela relampeja no momento de um perigo. Cabe ao materialista histórico fixar uma imagem do passado, como ela se apresenta, no momento do perigo, ao sujeito histórico, sem que ele tenha consciência disso. O perigo ameaça tanto a existência da tradição como os que a recebem (BENJAMIN, 2008, p. 224).

A fixação de uma imagem do passado se torna possível por intermédio da apropriação de uma reminiscência ou recordação, que podem escoar na cognoscibilidade política da relação entre o passado e o presente, uma vez que a imagem do passado concerne ao próprio presente: trata-se de uma imagem do presente, soterrada pelo fatalismo da continuidade abstrata. O subsídio estético de Baudelaire se transmuta em um tratamento epistêmico-político do tempo. Interromper o curso do mundo, interferir, numa renovada política de escrita, nos rumos da história. Considerando que a obra de Baudelaire se configura como consciente de seu próprio sentido histórico, será sob o signo do heroísmo que Baudelaire se referirá à possibilidade de uma atitude. $\mathrm{O}$ êthos benjaminiano se subsidia na crítica que recolhe as virtualidades intensivas das correspondências entre passado e presente, na direção de um "agora" de cognoscibilidade. A perda e o relampejo figuram como possibilidades de expressão linguística da relação do presente com o passado, exercício identificado por Benjamin na obra de Baudelaire. As ruínas do há pouco novo (MURICY, 1998, p. 208) estão espalhadas na obra de Baudelaire e permitem a Benjamin a consolidação do conceito 
de imagem dialética. $\mathrm{Na}$ materialidade dos poemas, a suspensão do fardo da continuidade. No transitório, a morada de um novo abrigo para o ser da poesia. $\mathrm{O}$ enfrentamento da condição de fetiche da mercadoria encontra em Baudelaire possíveis expressões da conexão do poeta com a perda da dignidade da poesia e a inauguração de um eu lírico que tende à composição de uma sensibilidade que não se abstrai do presente. Benjamin assim considera o problema específico evocado por Baudelaire em relação à modernidade - a relação entre as massas e a prostituição:

Um dos arcanos que só com a cidade grande foi revelado à prostituição é a massa. A prostituição inaugura a possibilidade de uma comunhão mística com a massa. O surgimento da massa é, contudo, simultâneo ao da produção em massa. A prostituição parece conter ao mesmo tempo a possibilidade de sobreviver num espaço vital, onde mais e mais os objetos de nosso uso mais íntimo se tornaram artigos de massa. Na prostituição das grandes cidades, a mulher se torna artigo de massa (BENJAMIN, 2000, p. 161-162).

As massas, a repetição, a prostituição, a contrapartida psíquica a economia do invólucro de novidade sobre o que se repete; são temas trabalhados por Benjamin em sua dedicação a compreensão do sentido histórico da estética de Baudelaire.

O contato com a obra de Charles Baudelaire abre novas possibilidades para as reflexões benjaminianas, na medida em que o poeta francês fertiliza suas considerações sobre a crítica e sobre a modernidade como uma atitude - como a constituição de um êthos - diante de um tempo que não é linear nem progressivo. A respeito de As flores do mal, Benjamin frisa justamente o efeito do tempo como fator determinante em sua recepção - em outras palavras, sua mortificação: "Baudelaire escreveu um livro que, a priori, tinha poucas perspectivas de êxito imediato junto ao público. [...] O leitor, para quem havia se preparado, ser-lhe-ia oferecido pelo período seguinte" (BENJAMIN, 2000, p. 103).

Mas o que o crítico alemão enxerga em Baudelaire não lhe fornece elementos que se limitam a subsidiar suas formulações acerca da crítica literária; mais do que exemplificar a gradativa transição entre teor coisal e teor de verdade através de um processo de mortificação, Baudelaire teria operado, ele mesmo, uma certa atitude crítica no que diz respeito à relação entre passado e presente e às ruínas de sua época. Condenando os pintores que lhe eram contemporâneos - desdenhosos dos fenômenos 
estéticos típicos da vida moderna e saudosos de um ideal de beleza que se manifestaria integralmente na aparência de uma obra - o autor de As flores do mal reivindica uma atenção refinada e um trabalho sobre aquilo que, por ser próprio ao presente, é instável e movediço. Essa relação positiva com o presente, no entanto, não exclui uma relação não-nostálgica com o passado; trata-se, na modernidade, de avaliar criticamente a tradição, despojando-se daquilo que nela já não responde aos anseios do atual, e extraindo dela o que poderia interferir e abrir novas possibilidades no presente. Daí a afirmação de Benjamin, em Paris do Segundo Império, de que a modernidade designa, a um só tempo, uma época e "a força que age nessa época e que a aproxima da antiguidade" (BENJAMIN, 2000, p. 80).

Um êthos baudelaireano da modernidade, portanto, consistiria numa espécie de sutura ativa entre passado e presente, muito distante da nostalgia imobilizadora e do "prazer efêmero da circunstância" (BAUDELAIRE, 2006, p. 859). Discorrendo sobre o conceito de alegoria, Gagnebin relaciona-o à obra de Baudelaire, precisamente nessa tensão entre-tempos: "É o choque entre o desejo de eternidade e a consciência aguda da precariedade do mundo que, segundo Benjamin, está na fonte de inspiração alegórica" (GAGNEBIN, 2011, p. 37). No caso do poeta, é da cidade de Paris que surgirão as imagens alegóricas a partir das quais ele gesta sua obra, ela mesma uma tomada de posição em relação à época que lhe coube viver - uma atitude, um êthos. Não apenas as ruínas da obra baudelaireana, reveladas por seu processo de mortificação, intensificam algumas reflexões importantes de Walter Benjamin; é que o próprio Baudelaire a constrói sob o signo da destruição - das ruínas concretas de uma Paris que sofre muito rapidamente os efeitos das reformas do Barão de Haussmann. ${ }^{4}$ Diante do diapasão que oscila entre a destruição de uma cidade que parecia eterna e a marca da novidade incessante, ele não chora o passado perdido nem louva as promessas do progresso - o que seriam indícios de uma vinculação um tanto incauta com um "tempo homogêneo e vazio"; sua atitude ancora-se na assunção de uma atitude política diante do passado e do presente - a instauração de uma distância crítica: reconhecendo que Paris e ele próprio já não são o que eram, Baudelaire pode separar o fardo da tradição estagnada

\footnotetext{
${ }^{4}$ George-Eugène Haussmann, prefeito do antigo departamento do Sena, responsável pelas transformações que forjaram a moderna arquitetura urbana de Paris. Esteve na condição de prefeito de 1853 a 1870.
} 
daquilo que, no passado, precisa ser salvo, produzindo uma interrupção na aparente indefectibilidade do presente. Se Benjamin pode ser creditado por elucidar a conexão inexorável entre cidade e modernidade na obra de Baudelaire (GAGNEBIN, 2011, p. 47), o poeta é um dos subsídios do tratamento político da história na obra do pensador alemão.

É mérito da interpretação benjaminiana ter mostrado como
estes dois temas, cidade e modernidade, são ao mesmo tempo
determinantes e inseparáveis na obra de Baudelaire. [...] o que liga a
poesia da cidade e a teoria da modernidade, em Baudelaire, é o tema
do transitório, da caducidade e da morte (GAGNEBIN, 2011, p. 47).

Persistindo em nossa proposição de que a tarefa filosófica e política assumida por Walter Benjamin encontra importantes subsídios na leitura que o pensador estabelece sobre a poética e a prosa de Charles Baudelaire, compreendemos que aproximar-se da cidade como índice material do sentido de modernidade se realiza como instauração de um abrigo para o ínfimo, para a particularidade. Sem a defesa de que a interrupção do curso do mundo possa ser encaminhada, também, à interrupção do progresso, não se procederia, em Benjamin, ao escrutínio do passageiro e dos apelos dos vencidos. O historiador lida com imagens: aquilo que, do passado, se destaca da certeza do acontecido, aquilo que, do tempo, se separa de sua pressuposta sucessão. Por isso, também, a recorrência a uma memória que não se resguarda como propriedade de reconhecimento de si, mas matéria espessa de que se pode apoderar, politicamente e esteticamente.

Defende-se, portanto, que distância e proximidade sejam condições cruciais para a compreensão do exercício benjaminiano em relação a poética e prosa de Baudelaire, ao mesmo tempo em que se revelam como essenciais para a compreensão da tarefa que o pensador coloca para si, para o próprio historiador materialista. Podemos defender que atentar-se ao que é próximo permite dissolver a facticidade do que é histórico. Mesmo com toda a controvérsia surgida em torno da interpretação de Benjamin em relação a Baudelaire - ou mesmo, exatamente por conta do que a controvérsia permite acessar - por parte de representantes do chamado Instituto de Pesquisa Social ${ }^{5}$ de Frankfurt,

\footnotetext{
${ }^{5} \mathrm{O}$ que se indica, por exemplo, nas correspondências trocadas entre Benjamin e Adorno. Ver Adorno (2012).
} 
encontramos preciosos vestígios do que o pensador articula como um êthos em suas interpretações sobre Baudelaire. Sabemos que distância e proximidade estão em jogo na elaboração de alguns conceitos forjados por Benjamin, tais como o conceito de aura e a centralidade da rememoração na proposição de uma historiografia materialista. A atualização é uma forma de desviar-se da compulsoriedade do continuum, o que aparece de forma explícita no texto derradeiro de Walter Benjamin, as célebres Teses sobre o conceito de história. Realiza-se a atualização não por capricho ou persistência na intencionalidade do historiador/pensador, mas por intermédio da elaboração de um êthos, ou seja, de uma atenção ao transitório, de uma preocupação com o caráter descontínuo da própria escrita, da assunção de um compromisso ético com o que fora silenciado e esmagado, com o próprio esquecimento. A modernidade se configura como a defesa de uma energia da qual se pode lançar mão epistemologicamente e politicamente para garantir a transmissão do que foi esquecido e que concerne, como já apontado anteriormente, ao presente, para a instauração do atual. Distância e proximidade estão em jogo para a defesa de uma ciência histórica que não encontra nexos pela contiguidade ou pela sucessão, mas para que se possa defender uma experiência com o passado (BENJAMIN, 2008, p. 231). Sob o signo da caducidade e da morte, Charles Baudelaire já havia composto imagens incontornáveis da proximidade entre o início da vida e o seu ocaso, como se trata do poema Les Petites Vieilles de As Flores do Mal: "Já não viste que o esquife onde dorme uma velha/ É quase tão pequeno quanto o de um infante?" (BAUDELAIRE, 2006, p. 176). Sob tais imagens, o poeta deixa-se circundar pela articulação de limiares, espacialidades que se revelam como a não exclusão entre dentro e fora. Deixar-se levar pela coincidência aguda entre o que se inicia e o que se finda no espaço da própria escrita parece ter fornecido à Benjamin alguns elementos cruciais para o encaminhamento do problema da compreensão histórica do tempo. No agora do texto, na correspondência entre o já findo e o presente, o pensador forja a sua própria tarefa epistêmica, a própria compreensão política daquilo que, tradicionalmente, só é compreendido sob o jugo da variação aparente daquilo que é.

O manejo de distância e proximidade também permite a defesa da articulação de um agora de cognoscibilidade, na também fundamental crítica a filosofia da representação. Captar o irreversível, assentar a tarefa histórica no reconhecimento de imagens que se dirigem ao presente e 
"despertar no passado as centelhas da esperança(...)" (BENJAMIN, 2008, p. 224) se nutrem, também, do desdobramento que o pensador realizou daquilo que foi colhido na leitura de Charles Baudelaire. Fundar um "agora" marcado por farpas do que se configura como messiânico aqui, podemos provisoriamente acatar o sentido de salvação em relação ao que foi esquecido e esmagado - encontra uma proveniência na interpretação de Baudelaire. Evidentemente que não podemos esquecer que as supostas prescrições em relação à tarefa do historiador materialista não se apresentam de forma autoritária, mas indicam a magnitude do reconhecimento do próprio Benjamin da oportunidade que a época aguda em que ele se encontrava poderia oferecer para o enfrentamento da barbárie. Sob a ameaça política - efetivamente materializada - do aniquilamento e a incapacidade de se articular uma oposição ao nazismo, parece que Walter Benjamin procura desdobrar conceitualmente aquilo que reconhecera na perspectiva estética de Baudelaire. A distância não apenas é constatada, mas fundada, traçada.

$* * * *$

Distância e proximidade são dois aspectos essenciais do exercício teórico e político defendido por Walter Benjamin, reconhecíveis na proposição de um êthos para o crítico e o historiador. Nossa argumentação visou alcançar momentos da obra de Benjamin em que a interpretação de Baudelaire pelo pensador abriga parte do sentido de seu procedimento teórico em relação, por exemplo, ao tempo histórico. Desdobramento e atualização são duas categorias que podem ser destacadas do esforço que empreendemos. Entendemos que a espessura de uma obra de arte e, mais ainda, a própria espessura temporal daquilo que aconteceu historicamente concernem à possibilidade de reconhecimento do presente, cindido de si próprio no gesto interpretativo que interroga continuísmos e unidade. Aproximar-se do presente indicaria, ainda de acordo com nossa interpretação, fundar uma distância em relação ao passado, como nos parece ser o sentido de uma atitude histórica que se recusa a ser apenas a expressão da continuidade. Como vimos, a interrupção não se realiza com a abstração do próprio presente.

Ainda uma vez, podemos sugerir uma forte aproximação entre Charles Baudelaire e Walter Benjamin, por intermédio da qual reconhecemos a velocidade com que podemos nos apropriar do pouco 
que a nossa própria época nos oferece, ao nos dirigirmos ao grão de possibilidade que ainda guarda um poder germinativo, embora o passado não seja vivível em si mesmo: as interpolações da rememoração dissociam aquele que lembra de si mesmo e, em termos políticos, o presente pode escrever história para si, a tradição dos oprimidos pode apropriar-se da rememoração e fundar nova luta sobre um passado esquecido. A interpretação da moda tanto em Baudelaire quanto em Benjamin anuncia o faro para a descontinuidade, imagem do tempo assentada, em Benjamin, na assunção de uma nova ética em relação ao acontecido. No caso de Baudelaire, trata-se de mais um fragmento de O pintor da Vida moderna:

O belo é constituído por um elemento eterno, invariável, cuja quantidade é excessivamente difícil de determinar, e por um elemento relativo, circunstancial, que será, se quisermos, sucessiva ou combinadamente, a época, a moda, a moral, a paixão. Sem esse segundo elemento, que é como o invólucro aprazível, palpitante, aperitivo do divino manjar, o primeiro elemento seria indigerível, inapreciável, não adaptado e não apropriado à natureza humana (BAUDELAIRE, 2006, p. 852).

Os dois elementos que constituem o belo fazem menção à fugacidade da moda. Um caso de citação do passado. "A moda tem um faro para o atual, onde quer que ele esteja na folhagem do antigamente. Ela é um salto de tigre em direção ao passado. Somente, ele se dá numa arena comandada pela classe dominante." (BENJAMIN, 2008, p. 230).

O passado possui valor histórico, em estética também se trata de referir-se à espessura do próprio tempo, desdobrada na citação, ou seja, na história. Apropriar-se da velocidade com que a moda salta em direção ao passado é procurar alojar, na precariedade inerente ao nosso presente, a remissão a um tempo perdido e, dialeticamente, inacabado. A reivindicação desse exercício para o pensamento se articulou nos escritos do pensador marcado pelas especificidades da época em que coube viver. Distintas imagens da tensão entre distância e proximidade se forjaram na escritura de Walter Benjamin. Voltar-se a obra de Charles Baudelaire também instrumentalizou o pensamento que defende que se trata, para a ciência histórica, de estabelecer uma experiência com o passado. Possivelmente, na recordação de infância de Walter Benjamin sobre a notícia da morte de um primo do seu pai, na textualidade do escrito, já se exprimem altos esforços em relação à legibilidade do passado que só se desdobra na atualidade, no 
agora. Algo não havia sido narrado pelo pai no leito do infante Benjamin, mesmo que o narrador tivesse apresentado pormenores da morte de um homem velho que pouco significava para a criança:

(...) ficou-me na memória o meu quarto nessa noite, como se soubesse que um dia ele voltaria a dar-me que fazer. Quando já era adulto, soube que o primo tinha morrido de sífilis. O meu pai tinha entrado para não ficar sozinho. Mas quem ele procurava era o meu quarto, e não eu. Nenhum deles precisava de confidente (BENJAMIN, 2013, p. 95).

Nem o pai nem o quarto precisavam de confidente. Aquele quarto lembrado guardava uma das linhas frisadas pela recordação, quando, já adulto, o pensador escreve sobre o século XIX por intermédio de suas lembranças, extravasadas pelo estatuto político da possível relação que se pode estabelecer com o passado. A estética de Baudelaire, discutida em textos posteriores do pensador, auxilia Benjamin a defender uma perspectiva teórica e política sobre o tempo histórico, problema evocado e enfrentado de muitas formas no devir da obra. A estética de Baudelaire, na interpretação benjaminiana, assume uma proveniência na proposição de um êthos, comprometido com o seccionamento do tempo, com a dissociação do presente em relação a sua própria evidência e com a articulação de uma cognoscibilidade frágil, mas arguta, urgente e que aponta para múltiplas possibilidades de interpretação. Debruçar-se sobre textos nem sempre contemporâneos de Benjamin forneceu-nos imagens importantes de um exercício do pensamento sobre a fugacidade daquilo que há pouco tínhamos diante de nós, transmitido a nós, afastado de nós, e que concerne a nós, que possui valor histórico, mas se encontra, potencialmente, postergado em sua legibilidade. O transitório também pode ser considerado como índice daquilo que consideramos histórico e, na duração do poema e da obra de Baudelaire, Walter Benjamin alojou-se como possível intérprete, atento à incontornável tarefa de transmitir algo que não tinha certeza se chegaria ao seu destinatário, ou mesmo, se teria um destinatário. Benjamin se apropria de Baudelaire para também defender uma feição histórica ao presente, sem incorrer em uma idealização do tempo. Suas obras se encontram no tempo estendido para além do texto, a partir do texto. 


\section{Referências}

ADORNO, T. Correspondência. São Paulo: Editora Unesp, 2012.

AGAMBEN, G. Infância e história: Destruição da experiência e origem da história. Belo Horizonte: Editora UFMG, 2005.

BAUDELAIRE, C. Poesia e prosa: volume único. Rio de Janeiro: Nova Aguilar, 2006

BENJAMIN, W. Magia e técnica, arte e política. São Paulo: Brasiliense, 2008.

BENJAMIN, W. As afinidades eletivas de Goethe In: . Ensaios reunidos: escritos sobre Goethe.1ed. São Paulo: Editora 34, 2009. p. 11-121. BENJAMIN, W. Espaços livres para alugar In: . Rua de mão única: Infância Berlinense: 1900.1ed. Belo Horizonte: Autêntica Editora, 2013. p. 50-51.

BENJAMIN, W. Notícia de uma morte .In: .Rua de mão única: Infầncia Berlinense: 1900. 1ed. Belo Horizonte: Autêntica Editora, 2013.p. 95.

BENJAMIN, W. Charles Baudelaire: Um lírico no auge do capitalismo. São Paulo: Brasiliense, 2000.

CASTRO, C. A alquimia da crítica: Benjamin e as afinidades eletivas de Goethe. Rio de Janeiro: Paz e Terra, 2011.

GATTI, L. Walter Benjamin e o Surrealismo: escrita e iluminação profana. Artefilosofia, Ouro Preto, n. 6, p.74-94, 2009. Disponível em: <http://www. raf.ifac.ufop.br/pdf/artefilosofia_06/artefilosofia_06_01_dossie_walter benjamin_08_luciano_gatti.pdf/>Acesso em: 20 set. $201 \overline{7}$.

GAGNEBIN, J.M. História e narração em Walter Benjamin. São Paulo: Perspectiva, 2011.

MURICY, K. Alegorias da dialética. Rio de Janeiro: Relume Dumará, 1998.

Recebido em: 30 de outubro de 2017. Aprovado em: 06 de fevereiro de 2018. 